\title{
Extraction and Purification of Haemophilus influenzae Type b Lipooligosaccharide by Modified Phenol Method
}

\author{
Amin Arsang ${ }^{1,2}$, Shamsi Yari ${ }^{2}$, Morteza Masoumi ${ }^{2}$, Ali Nour Neamatollahi ${ }^{2}$, Farzam Vaziri $^{2}$, \\ Mehdi Nejati ${ }^{3}$, Ahmad Reza Bahremand ${ }^{2}$, Seyed Davar Siadat ${ }^{1,2 *}$ \\ 1 Department of Microbiology, Pasteur Institute of Iran, Tehran, Iran \\ 2 Department of Mycobacteriology \& Pulmonary Research, Pasteur Institute of Iran, Tehran, Iran \\ 3 Department of Bacterial vaccine, Pasteur Institute of Iran, Tehran, Iran
}

Received Feb 16, 2014; Accepted May 27, 2014

\begin{abstract}
:
Introduction: Haemophilus influenzae type b (Hib) is a Gram negative bacterium and one of the causative agents of acute bacterial meningitis, especially in infants and children less than 5 years old. Lipooligosaccharide (LOS), one of the virulence factors which plays an important role in pathogenesis of Hib, has multiple applications in diagnosis and conjugate vaccines. In this study, LOS extracted from two Hib standard strains (ATCC 39930 and ATCC 10214) were compared. Methods: LOS was extracted by a modified hot phenol method from the aqueous and phenol phase and its concentration and purity assayed. Protein contaminations of the samples were determined spectrophotometrically and their endotoxin contents were assayed by the Limulus amebocyte lysate (LAL). Result: The yield of the extracted LOS from strain ATCC10214 was about $475 \mu \mathrm{g} / \mathrm{ml}$ and the protein contaminations of the samples were approximately $0.07 \mathrm{mg} / \mathrm{ml}$, whereas strain ATCC39930 yielded $520 \mu \mathrm{g} /$ $\mathrm{ml}$ of LOS with protein contamination of $0.08 \mathrm{mg} / \mathrm{ml}$. The results showed that the production of LOS by both strains was similar and the variation observed was not statistically significant $(\mathrm{p}<0.001)$. Vac Res, 2014, 1 (1): 28-30
\end{abstract}

Keywords: Haemopbilus influenzae type b, Lipooligosaccharide, Meningitis.

\section{INTRODUCTION}

Haemophilus influenzae is a Gram-negative, non-motile and fastidious bacterium classified into two groups of capsular and non-capsular strains [1]. The encapsulated strains are serologically subdivided into $6(\mathrm{a}-\mathrm{f})$ distinct types based on the capsular antigen. H. influenzae type $b$ (Hib) is an important cause of serious invasive infections in children less than five years old and meningitis is a frequent consequence of invasive Hib infection [2, 3].

\section{*Corresponding Author: Seyed Davar Siadat}

Department of Mycobacteriology and Pulmonary Research, Pasteur Institute of Iran, No. 69, Pasteur Ave, Tehran, Iran, 1316943551.

Email: d.siadat@gmail.com

Tel /Fax: +98 21 66969291,
Several factors such as the membrane proteins HMW1, HMW2, P5, Hap, P2 and P6 contribute to the pathogenesis of $H$. influenzae. Although the capsular polysaccharide is the key virulence determinant, this pathogen also expresses an O-deacylated lipooligosaccha-ride (LOS) consisting of a mainly conserved triheptose backbone attached to a core region, covalently linked to lipid A [4-8]. Lipid A is a natural ligand for the MD2- Toll-like receptor 4 (TRL4) complex with a pivotal role in producing inflammatory responses $[8,9]$. The observed inter- and intra-strain heterogeneity of LOS has been attributed to the oligosaccharide extensions stemming from the triheptose core region $[9,10]$. Lipid A constitutes about $60 \%$ of LOS while the remainder of this molecule consists of hydrophilic polysaccharides [11]. It appears that the structure of lipid A in different strains of Hib is relatively conserved as it has 
been shown that nearly $50 \%$ of a large collection of Hib strains shared at least one epitope in lipid A region [12, 13].

The ability of LOS to up and down-regulate the production of inflammatory cytokines and proinflammatory markers, albeit to a lesser extent than LPS, and its ubiquitous presence in all $H$. influenzae strains makes this molecule an attractive vaccine candidate. The detoxified LOS, conjugated with outer membrane proteins strains lacking the capsule, has been used as a candidate for vaccination against the non-typable strains [10]. In addition, the immunostimulatory properties of LOS might be considered of value for potential adjuvant developments as a TLR4 agonist [8,9]. Moreover, LOS could be used as a good antigen for diagnostic applications. In this study, LOS was extracted from two different strains of Hib (strains ATCC39930 and ATCC10214) and their concentrations and purities compared.

\section{MATERIALS AND METHODS}

Bacterial strains and the cell biomass production. Standard strains of Hib (Pasteur Institute of Iran, Department of Bacterial Vaccine production)

Were cultured overnight at $36.6+-.5^{\circ} \mathrm{C}$ in Brain Heart Infusion agar (Merck, Germany) supplemented with 1\% hemin (Sigma-Aldrich, Germany) and $0.01 \%$ Nicotinamide Adenine Dinucleotide (NAD; Mast Group, UK). This culture was used to inoculate 21 Casamino acids and yeast extract (CY) medium (in a 51 flask), supplemented with $0.02 \mathrm{~g} / 1$ of NAD and $0.04 \mathrm{~g} / 1$ of hemin (pH 7.3), incubated for $24 \mathrm{~h}$ at $37^{\circ} \mathrm{C}$, to obtain the seed culture [14]. The seed culture was added to a 601 industrial fermenter containing $351 \mathrm{CY}$ medium and after $12 \mathrm{~h}$, the fermentation process was stopped by addition of $10 \%$ phenol and the biomass was harvested by centrifugation at $4000 \mathrm{rpm}$ for $45 \mathrm{~min}$ at $4^{\circ} \mathrm{C}$.

LOS purification. LOS was extracted by a modified Westphal and John method [15]. Briefly, the bacterial biomass was suspended in $170 \mathrm{ml}$ distilled water, followed by addition of $190 \mathrm{ml} 90 \%(\mathrm{v} / \mathrm{v})$ hot phenol $\left(66^{\circ} \mathrm{C}\right)$ and the mixture was stirred then for $14 \mathrm{~min}$ at $66^{\circ} \mathrm{C}$. The bacterial suspension was kept on ice and the temperature was lowered to $0^{\circ} \mathrm{C}$ and then centrifuged $\left(8500 \times \mathrm{g}, 4^{\circ} \mathrm{C}\right)$ for 15 min. LOS was extracted by the addition of $25 \%$ and $100 \%$ $(\mathrm{v} / \mathrm{v})$ cold ethanol $\left(4^{\circ} \mathrm{C}\right)$ to the aqueous and phenol phase, respectively. One hundred $\mathrm{ml}$ of $75 \%(\mathrm{v} / \mathrm{v})$ cold $\left(4^{\circ} \mathrm{C}\right)$ ethanol was added to the supernatant of the aqueous phase and kept at $4{ }^{\circ} \mathrm{C}$ for $6 \mathrm{~h}$, then centrifuged and LOS-containing pellet dissolved in distilled water. The pellet obtained from phenol phase was dissolved in distilled water and centrifuged as above for $1 \mathrm{~h}$ and the LOS-containing supernatant was kept for the final purification. To reduce the nucleic acids and protein contaminations, DNase, RNase and proteinase $\mathrm{K}$ were used and for precipitation, $1 \mathrm{~g}$ trichloroacetic acid (TCA) per $20 \mathrm{ml}$ of the extracted sample was added and the solution was kept at $4^{\circ} \mathrm{C}$ for $3 \mathrm{~h}$. Finally, the TCA-treated samples were centrifuged $\left(2000 \times \mathrm{g} 4^{\circ} \mathrm{C}\right.$ for $\left.10 \mathrm{~min}\right)$ and dialyzed against deionized water for $72 \mathrm{~h}$.
Physicochemical analysis. The dialyzed samples were analyzed by $10 \%$ SDS-PAGE and stained by silver nitrate [15]. LOS concentration was assayed colorimetrically and the absorbance was measured at $595 \mathrm{~nm}$. The concentration of LOS in the samples was calculated against a curve drawn by using E. coli LPS as standard [16]. Protein content of the extracted samples was measured spectophotometrically using NanoDrop (Thermo Scientific, USA). The endotoxin levels of the samples were assayed by choromogenic Limulus amebocyte lysate (LAL) method [15].

\section{RESULTS}

In batch fermentation under submerged culture condition, the yield of the biomass was $120 \mathrm{~g}$ for Hib strain ATCC39930 and $107 \mathrm{~g}$ for Hib strain ATCC10214. LOS concentration was calculated based on the standard curve obtained by the linear equation of $y=0.001 x-0.0003$ (Fig. 1A).

The optical density (OD) for Hib strain ATCC39930 was 0.520 and its calculated concentration was $520 \mu \mathrm{g} / \mathrm{ml}$, whereas the OD of Hib strain ATCC10214 was 0.475 equaling to a concentration of $475 \mu \mathrm{g} / \mathrm{ml}$ (Fig. 1A). The silver-stained SDS-PAGE of the LOS from both strains showed no detectable protein contamination (Fig. 1B).
A

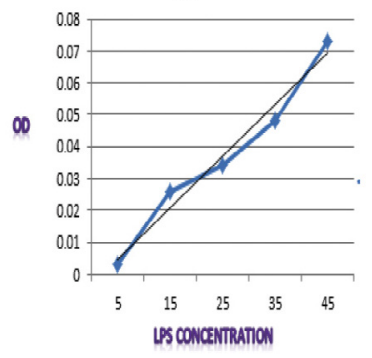

B

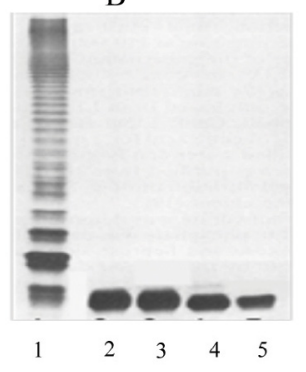

Fig. 1: A) Standard curve representing OD vs. standard LPS concentration. B) Silver-stained SDS-PAGE of the extracted LOS from strains ATCC39930 and ATCC10214. Lane 1: standard LPS, lanes 2 and 3: Hib strain ATCC39930, lanes 4 and 5: Hib strain ATCC10214.

The amount of protein contaminations in the extracted samples were $0.08 \mathrm{mg} / \mathrm{ml}$ for Hib strain ATCC39930 and 0.07 $\mathrm{mg} / \mathrm{ml}$ for Hib strain ATCC10214. The endotoxin levels of the extracted samples were measured by chromogenic LAL test and were $1420 \mathrm{EU} / \mathrm{ml}$ for Hib strain ATCC39930 and $1480 \mathrm{EU} / \mathrm{ml}$ for Hib strain ATCC10214.

\section{DISCUSSION}

LOS of $H$. influenzea is a heterogenous and complex glycolipid which plays a critical role in the virulence of Hib [17]. The difference between LOS and LPS is that in LOS, the variable branched region or $\mathrm{O}$-antigen is a non-repeating unit. This structure can be isolated from a number of bacteria such as 
Haemophilus ducreyi, Branhamella catarrhalis, Neisseria meningitidis, Neisseria gonorrhoeae and Bordetella pertussis [18]. LOS could induce both innate and acquired immune responses by two component polysaccharide and lipid moiety separately. With the increasing application of LOS, establishing a protocol for culturing Hib and purification of LOS could be of value for research and development of subunit vaccines. Although the optimized phenol and butanol extraction methods are the two well-established procedures for extraction and purification of LPS and LOS but modifications to these methods have been reported $[15,18]$. However, in comparison the optimized phenol extraction method has given the highest LPS yield and the lowest protein contamination, although proteinase K method has been reported as less cumbersome [19]. In this study, a modified hot phenol method followed by the use of proteinase $\mathrm{K}$ digestion of the bacterial proteins and nucleases, resulted in preparation of a high quality LOS, free of protein and nucleic acids contaminations. The main aim of this study was the extraction of purified LOS for further application as an antigenic macromolecule. The use of highly-purified LOS can lead to the induction of specific immune responses including the innate and acquired immunity [9].

In conclusion, although the yield of the biomass production by two strains of Hib have been shown equal in batch fermentation, extracted LOS were $1420 \mathrm{EU} / \mathrm{ml}$ for Hib strain ATCC39930 and $1480 \mathrm{EU} / \mathrm{ml}$ for Hib strain ATCC10214. According to chemical analysis of the extracted sample, we finally conclude that optimized phenol extraction is the best method with the least protein and nucleic acid contaminations and would be recommended to extract and purity Hib LOS for further application.

\section{ACKNOWLEDGEMENTS}

This study was supported by Grant No. 571 of Pasteur Institute of Iran.

\section{CONFLICT OF INTEREST}

No potential conflicts of interest were disclosed.

\section{REFERENCES}

1. Sukupolvi-Petty S, Grass S, St Geme W 3rd. The Haemophilus influenzae Type $\mathrm{b} h c s A$ and $h c s B$ gene products facilitate transport of capsular polysaccharide across the outer membrane and are essential for virulence. J Bacteriol. 2006; 188 (11): 3870-7.

2. Kelly DF, Maxon ER, Pollard AJ. Haemophilus influenzae type b conjugate vaccines. Immunol. 2004; 113 (2): 163-174

3. Morris SK, Moss WJ, Halsey N. Haemophilus influenza type b conjugate vaccines use and effectiveness. Lancet Infect Dis. 2008; 8 (7): 435-43.

4. Cotter SE, Yeo HJ, Juehne T, St Geme JW 3rd. Architecture and adhesive activity of the Haemophilus influenzae Hsf adhesin. J Bacteriol. 2005; 187 (13): 4656-64.

5. Kyd JM, Cripps AM, Novotny LA, Bakaletz LO. Efficacy of the 26-kilodalton outer membrane protein and two 55 fimbrin-derived immunogens to induce clearance of nontypeable Haemophilus influenzae from the rat middle ear and lungs as well as from the Chinchilla middle ear and nasopharynx. Infect Immun. 2003; 71 (8): 4691-9.

6. Fink DL, Buscher AZ, Green B, Fernsten P, St Geme JW 3rd. The
Haemophilus influenzae Hap autotransporter mediates microcolony formation and adherence to epithelial cells and extracellular matrix via binding regions in the Cterminal end of the passenger domain. Cell Microbiol. 2003; 5 (3): 147-86.

7. Haase EM, Morse GD, Murphy TF. Mapping of bactericidal epitopes on the $\mathrm{p} 2$ porin protein of nontypeable Haemophilus influenzae. Infect Immun. 1994; 62 (9): 3712-22.

8. Choi J, Cox AD, Li J, McCready W, Ulanova M. Activation of innate immune responses by lipooligosaccharide Haemophilus influenzae. Clin Vaccine Immunol. 2014; 21 (5): 769-76.

9. Bryant CE, Spring DR, Gangloff M, Gay NJ. The molecular basis of the host response to lipopolysaccharide. Nature Rev Microbiol 2010; 8 (1): 8-14.

10. Schweda EK, Richards JC, Hood DW, Moxon ER. Expression and structural diversity of the lipopolysaccharide of Haemophilus influenzae: implication in virulence. Int J Med Microbiol 2007; 297 (5): 297-306.

11. Zamze SE, Moxon ER. Composition of lipopolysaccharide from different capsular serotype of Haemophilus influenzae. J Gen Microbiol. 1987; 133 (6) :1443-51

12. Raetz CR. Biochemistry of endotoxins. Annu Rev Biochem. 1990; 59: $129-70$

13. Apicella MA, Dudas KC, Compagnari A, Rice P, Mylotte J M, Murphy TF. Antigenic heterogeneity of lipid A of Haemophilus influenzae. Infect Immun. 1985; 50 (1): 9-14.

14. Takagi M, Zangirolami TC, Tanizaki MM, Cabrera-Crespo J. Improvement of simple cultivation conditions for polysaccharide synthesis by Haemophilus influenzae type b. Communicating Current Research and Educational Topics and Trends in Applied Microbiology. 2007; 602-608.

15. Salmani AS, Siadat SD, Norouzian D, Ahmadi H, Nejati M, Tabaraie B, Abbasi M, Karbasian M, Mohabati Mobarez A, Shapouri R, Karbasian M. Optimization of Brucella abortus S99 lipopolysaccharide extraction by phenol and Butanol methods. Res J Bio Sci. 2008; 3 (6): 576-80.

16. Moreno E, Pitt MW, Jones LM, Schurig GG, Berman DT. Purification and characterization of smooth and rough lipopolysaccharides from Brucella abortus. J Bacteriol. 1979; 138 (2): 361-9.

17. Preston A, Mandrell RE, Gibson BW, Apicella MA. The lipooligosaccharid of pathogenic gram-negative bacteria. Crit Rev Microbiol. 1996; 22 (3): 139-80.

18. Swords WE, Chance DL, Cohn LA, Shao J, Apicella MA, Smith AL. Acetylation of the lipooligosaccharide of Haemophilus influenzae and colonization: an htrb mutation diminishes the colonization of human airway epithelial cells. Infect Immun. 2002; 70 (8): 4661-8.

19. Kimura A., Hansan EJ. Antigenic and phenotypic variations of Haemophilus influenzae type b lipopolysaccharide and their relationship to virulence. Infect Immun. 1986; 51 (1): 69-79. 